\title{
Comunidade de Prática no setor de educação com enfoque na inovação
}

\section{The Use of Community of Practice for the innovation in educational sector}

\author{
Fabiana de Agapito Kangerski Mestre em Administração. Instituto Federal de Educação de Santa Catarina (IFSC) - Brasil. \\ fabiana.agapito@ifsc.edu.br \\ Gertrudes A. Dandolini Doutora em Engenharia de Produção - Universidade Federal de Santa Catarina (UFSC) - Brasil - \\ gertrudes.dandolini@ufsc.br \\ João Artur de Souza Doutor em Engenharia de Produção - Universidade Federal de Santa Catarina (UFSC) - Brasil - \\ jartur@gmail.com \\ Julieta K. W. Wilbert Doutora em Engenharia e Gestão do Conhecimento - Universidade Federal de Santa Catarina (UFSC) \\ - Brasil - researcher.wilbert@protonmail.com
}

\begin{abstract}
RESUMO
Conhecimento, aprendizagem e inovação é uma tríade de vocábulos que deve estar presente em organizações de qualquer setor de atuação. Na educação, esforços têm sido empreendidos para tornarem as práticas mais condizentes com a tônica contemporânea. Diversos autores definem Comunidade de Prática (CoP) de formas distintas. Neste artigo uma CoP é conceituada como um grupo de pessoas voltadas a um processo de aprendizagem coletivo baseado em interações sociais. Assim, consiste de uma revisão bibliográfica sistemática, tendo como enfoque principal identificar como as CoPs têm sido aplicadas para a inovação no setor de educação. Analisou-se 23 artigos completos das bases de dados Scopus e Web of Science e se detectou que as CoPs, embora sejam estudadas sob perspectivas e domínios, e em diferentes segmentos educacionais, apresentam aspectos comuns, entre estes: a percepção da abordagem coletiva e social da aprendizagem e, principalmente, um campo fértil para a proliferação de conhecimentos e formação de identidade. Além disso, identifica-se uma predominância para o emprego de CoPs para a inovação de práticas pedagógicas.
\end{abstract}

Palavras-chave: Comunidade de Prática. Educação. Inovação.

\begin{abstract}
Knowledge, learning, and innovation is a triad of words that should be present in organizations in any sector of activity. In education, efforts have been made to implement practices that are more consistent with requirements of the contemporary world. Authors define Community of Practice (CoP) differently. In this paper a CoP is defined as a group of people focused on a collective learning process based on social interactions. Thus, it consists of a systematic literature review, with the main focus on identifying how CoPs have been applied for innovation in the education sector. Twenty-three complete articles from the Scopus and the Web of Science databases were analyzed in the current paper. The results showed that CoPs, although studied under different perspectives and domains, and in different educational segments, have common aspects, such as the perception of the collective and social approach of learning. Above all, a CoP is a fertile field for the proliferation of knowledge and identity formation of the group. In addition, there is a predominance of the use of CoPs for the innovation in pedagogical activities.
\end{abstract}

Keywords: Community of Practice. Education. Innovation. 


\section{INTRODUÇÃO}

O conhecimento hoje é reconhecido como um dos principais recursos para o sucesso de qualquer organização (LEE, 2016; WENGER, 2012; WENGER; SNYDER, 2000). Grande parte desta riqueza intangível reside no conhecimento não explicitado, ou seja, aquele que não está escrito, codificado ou formalizado (LEE, 2016). Segundo Tidd, Bessant e Pavitt (2008) a inovação é uma forma de combinação de novos conhecimentos, estejam eles explicitados ou baseados na experiência de cada um e ainda não formulados.

Uma Comunidade de Prática (CoP) é formada por pessoas que se envolvem em um processo de aprendizagem coletiva em um domínio compartilhado do esforço humano (WENGER, 2015. O termo adveio dos estudos de Lave e Wenger (1991) que, sob uma abordagem antropológica, enfatizaram que a aprendizagem ocorre sobretudo na interação social (SMITH; HAYES; SHEA, 2017). Trata-se de espaço privilegiado para identificação, aquisição, armazenamento e produção de conhecimentos, que viola a ideia convencional de que este pertence apenas aos seus indivíduos (BROWN; DUGUID, 2001). As CoPs baseiam-se em estruturas mais orgânicas e de participação voluntária que escapam das amarras hierárquicas tradicionais (WILBERT, 2019).

O conceito de CoP alcançou variados domínios científicos incluindo a Gestão do Conhecimento, aprendizagem organizacional, Ciências da Informação, Saúde, organizações sem finalidades lucrativas e Educação (COX, 2005; WENGER, 2015). O setor de educação tem no conhecimento e na aprendizagem um meio e um produto (WENGER, 2015) e traz desafios crescentes. Presença de tecnologias emergentes, alta conectividade, necessidade de acessibilidade e flexibilidade, mudanças nas ofertas e demandas de formação escolar e profissional, necessidade de práticas pedagógicas não tradicionais e que coloquem o aluno como protagonista, são alguns dos enfrentamentos a serem transpostos por este segmento nos seus diversos níveis. Assim, atualmente, a inovação na educação tem sido alvo de constantes estudos acadêmicos e esforços de gestores públicos e privados.

Este artigo tem como objetivo identificar como as CoPs têm sido utilizadas para a inovação no setor de educação. Wenger (2015) aponta que as primeiras aplicações de comunidades de prática nesse segmento têm sido na formação de professores e na prestação de apoio a colegas no desenvolvimento de suas funções, além da utilização como interação entre estudantes além das fronteiras das escolas. As CoPs no setor de educação são empregadas de maneiras distintas envolvendo discentes, docentes, tutores e mediadores até abordagens institucionais mais amplas. Considerando que as CoPs são voltadas para a aprendizagem social e se constitui de espaços privilegiados de captura e de construção de conhecimento (BROWN; DUGUID, 2001; CORREIA; PAULOS; MESQUITA, 2008;), torna-se relevante estudar de que forma o próprio segmento de educação faz uso da CoP, na perspectiva da inovação, a partir de estudos realizados, suas possíveis aplicações e resultados em um segmento no qual conhecimento é a matéria-prima principal.

Nessa linha, desenvolveu-se uma revisão sistemática integrativa com pesquisa em duas bases de dados tendo como base a pergunta norteadora principal: "Como as CoPs são empregadas no setor de educação, visando a inovação?"

Este trabalho está estruturado em cinco seções, incluindo esta introdução. Inicialmente, na revisão de literatura, apresentam-se conceitos, características e papel da CoP, relacionando-a com a inovação. A terceira seção descreve os procedimentos metodológicos. A quarta seção é dedicada a apresentar e analisar artigos de periódicos científicos a respeito da aplicação de CoPs no setor de educação. A pesquisa se encerra com indicações para a continuidade e aprofundamento de estudos.

\section{REVISÃO DA LITERATURA}

Com o intuito de elucidar o tema, nesta seção serão apresentados aspectos da literatura referentes ao conceito de CoPs e as inter-relações com a inovação. 


\subsection{As Comunidades de Práticas: um conceito em evolução}

As CoPs são entidades informais, que existem pelo estabelecimento de conexões voluntárias entre os seus membros e com a partilha específica de problemas ou áreas de interesse em comum (ARDICHVILI; PAGE; WENTLING, 2002). No conceito de Lave e Wenger (1991, p. 98) constituem-se de um "sistema de atividades no qual participantes compartilham entendimentos sobre o que se está fazendo, e o que isso significa para suas vidas e para a comunidade."

Inicialmente, os estudos de Lave e Wenger (1991) a respeito de CoPs estiveram centrados nas interações entre novatos e especialistas e como os recém-chegados criam uma identidade profissional em um ambiente social (LI et al, 2009; WENGER, 2012). Os citados precursores abordaram o termo "participação periférica legítima" para designar o movimento dos novatos que iniciam sua participação em uma comunidade de forma "periférica" e encaminham-se para o centro através do crescente envolvimento (SMITH; HAYES; SHEA, 2017). A chamada participação periférica legítima, o envolvimento ativo na prática, é identificado como um processo-chave na aprendizagem e que extrapola as relações tradicionais entre aluno e um mestre (CORREIA, PAULOS, MESQUITA, 2008; COX, 2005). Neste escopo, Brown e Duguid (1991) revelam que a aprendizagem não se limita na obtenção de fatos sobre o mundo, mas também de agir neste mundo de forma socialmente reconhecida. Os autores introduzem o termo "identidade", indicando que a aprendizagem envolve também a construção da identidade (BROWN; DUGUID, 1991).

Em 1998, no livro intitulado Communities of Practice: learning, meaning and identity, Wenger refina os estudos sobre CoP tendo como foco a aprendizagem no local do trabalho, socialização da aprendizagem e a identidade do indivíduo (LI et al., 2009). O cerne da teoria de Wenger é o que o conhecimento é gerado através do engajamento de pessoas em práticas sociais (COX, 2005; SMITH; HAYES; SHEA, 2017; WENGER, 2012).

Em 2002, na publicação Cultivating Communities of Practice de Wenger, McDermott e Snyder, o conceito mudou de foco e passou a ser aplicado como uma ferramenta gerencial que visa a competitividade organizacional e também como meio para promover inovação e abordagens criativas de problemas (COX, 2005; Ll et al., 2009; WILBERT, 2015).

Correia, Paulos e Mesquita (2008) apontam que diversos pesquisadores vêm contribuindo para a disseminação do conceito e que, embora ainda não possa se perceber um consenso, há alguns aspectos em comum, tais como: o seu caráter informal, as visões sobre aprendizagem; a presença na comunidade ser um ato voluntário motivado pelo desejo de discutir a sua prática e adquirir novos conhecimentos, a autoorganização do sistema, a não existência de relações hierárquicas e a diversidade na participação de membros.

Para fins deste artigo, tendo em vista a influência de Lave e Wenger (1991) e o fato de suas obras serem uma das mais citadas e influentes (COX, 2005) serão considerados os seus referenciais, incluindo estudos de autores que os levaram em consideração.

\subsection{Inovação e a Contribuição das Comunidades de Prática}

Embora seja um termo originário do meio empresarial, atualmente a inovação é reconhecida como uma necessidade em todos os setores, incluindo os sistemas educacionais. De maneira ampla, a inovação poder definida como um processo em que o conhecimento é adquirido, partilhado e assimilado com o objetivo de identificar oportunidades e criar conhecimentos, que é incorporado em produtos, serviços e processos, e visa a geração de valor (PLESSIS, 2007; TIDD; BESSANT, 2015).

O emprego do termo inovação no segmento educacional é polissêmico (LEAL-SOTO; HERNANDEZ; PARADA, 2016; TAVARES, 2019). O estudo de Tavares (2019) sobre a utilização do conceito de inovação na educação, constatou que o termo é empregado com uma ampla rede de significados, variando conforme epistemologia e ideologia predominante no processo educativo. Entre as conceitualizações levantadas pelo autor, estão as centradas na percepção da inovação como um processo que pode ser planejado e controlado 
enfatizando reformas e mudanças, as abordagens que enfatizam práticas educacionais que se distinguem das tradicionais e o emprego de novas tecnologias nas propostas pedagógicas.

A inovação requer criação e compartilhamento de conhecimentos que vão além do que está codificado ou que é disposto pelas interações via estruturas funcionais e formais da organização. Plessis (2007) argumenta que a partilha e a codificação do conhecimento tácito são fundamentais para a capacidade de inovação, e que um dos papéis da gestão do conhecimento é atuar para desenvolver a colaboração entre funcionários, clientes e fornecedores visando a transferência de conhecimento tácito e construção de knowhow coletivo. E neste ponto uma CoP pode desempenhar um papel importante.

As CoPs podem desenvolver várias atividades, como incluir pedidos de informação, troca de experiências, elaboração de projetos, mapeamento de lacunas de conhecimento, promoção de coordenação e sinergia entre membros, solução de problemas e recuperação de conhecimentos, desenvolvimento de novas estratégias e linhas de negócios (WENGER; SNYDER, 2000; WENGER, 2015). Observa-se o que foi ressaltado por Chu e Khosla (2009) de que as CoPs enfatizam não apenas o conhecimento tácito, mas também o explícito, permitindo a aprendizagem e induzindo a inovação para maximizar o valor de gestão do conhecimento. Há autores que mencionam que CoPs podem ser estimuladas institucionalmente visando a inovação, classificando-a como Método, Técnica e Ferramenta para a inovação (MTF-i) (WILBERT et al. 2017; WILBERT, 2019).

Wenger (2012) ressalta que gerir o conhecimento não é essencialmente um desafio tecnológico, mas sobretudo de desenvolvimento da comunidade, pois conhecimento sem utilização não apresenta valor. Li et al. (2009) enfatizam que as CoPs proporcionam um ambiente seguro para as pessoas se envolverem na aprendizagem através da observação e interação com especialistas e discussão entre colegas. Uma das contribuições das CoPs está no fortalecimento dos laços entre os indivíduos pertencentes ao mesmo grupo, oferecendo um mecanismo prático para ajudar os membros a partilharem e a interiorizarem o conhecimento tácito (CORREIA; PAULOS; MESQUITA, 2008).

Nem toda comunidade pode ser classificada como uma CoP (WENGER, 2015). Há três conceitos importantes que sustentam os princípios de uma CoP: o domínio, a identidade e a prática (COX, 2015; Ll et al., 2009; WENGER, 2015;). O domínio constitui a área do conhecimento que reúne a comunidade e lhe confere identidade, tornando-a diferente de um simples grupo de amigos ou rede de conexão entre pessoas (COX, 2015). Já a comunidade é conceituada como um grupo de pessoas para quem o domínio tem relevância e os seus membros estão dispostos a interagirem para aprenderem mutuamente (WENGER, 2015). Um terceiro conceito associado é o de prática, definida por Wenger (2015) como um conjunto de conhecimentos, métodos, histórias, casos, documentos que os membros compartilham e desenvolvem conjuntamente visando a solução de problemas recorrentes.

As CoPs podem assumir variados formatos e tamanhos. Podem ser grandes, pequenas, formadas apenas com membros da organização ou de várias organizações, presencial ou online ou com modelos mistos, podem ser apoiadas e incentivadas financeiramente e gerencialmente e, outras, podem ser completamente voluntárias ou invisíveis (WENGER; SNYDER, 2000; WENGER, 2015). Com a proliferação da internet, Correia, Paulos e Mesquita (2008) afirmam que as CoPs virtuais ou digitais, tal como podem ser denominadas, beneficiam-se das tecnologias colaborativas para reduzir as distâncias geográficas e gerar integração entre pares.

\section{PROCEDIMENTOS METODOLÓGICOS}

O presente artigo é uma revisão da literatura para identificar como as CoPs são empregadas no setor de educação, visando a inovação. Para a coleta de dados, o principal método adotado foi a Revisão Bibliográfica Sistemática (RBS), que teve procedimentos inspirados no modelo Roabmap desenvolvido por Conforto, Amaral e Silva (2011) e expresso na Figura1. 
Figura 1 - Modelo Roabmap

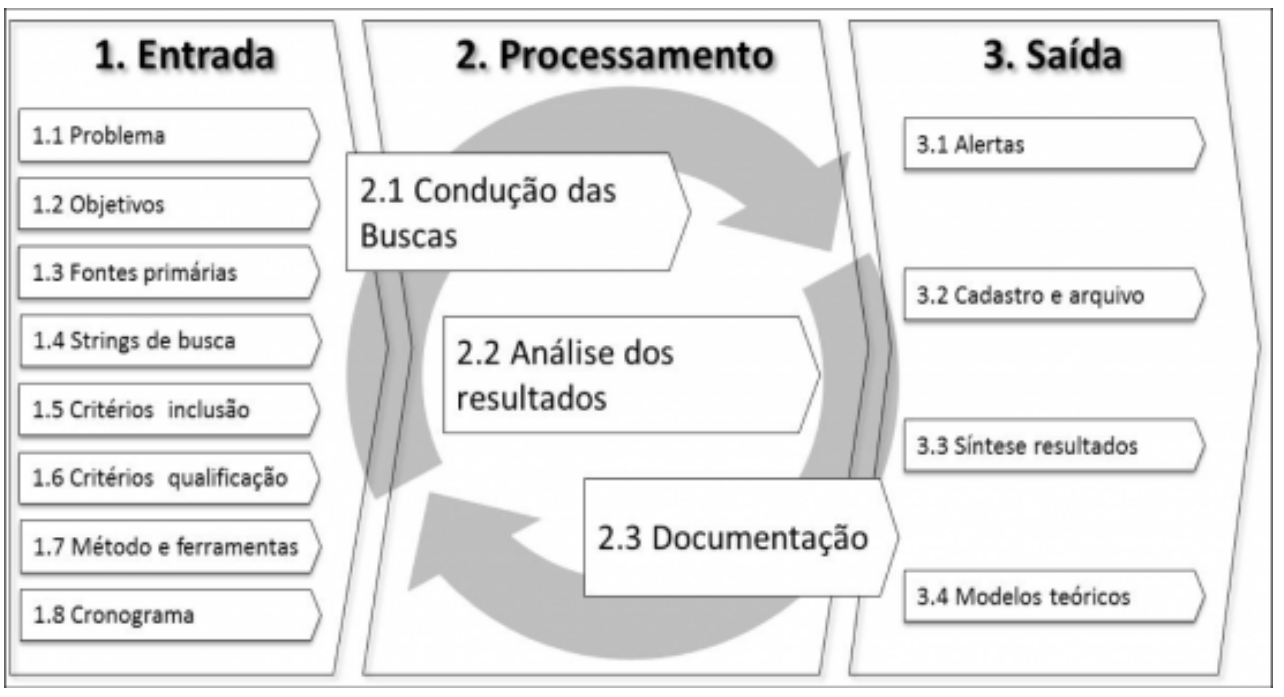

Fonte: Conforto, Amaral e Silva (2011).

A partir da pergunta de pesquisa inicial realizaram-se buscas preliminares nas bases Scopus e Web of Science. Os critérios de inclusão e qualificação foram artigos, revisados por pares e sem restrição de temporalidade.

Os strings de buscas iniciais foram estabelecidos, combinados e testados. Conforme os resultados obtidos, as palavras e os termos foram aprimorados com os operadores boleanos e as especificidades de cada base. Como resultado desta etapa, as palavras e os termos escolhidos em inglês foram "communities of practice" and "innovation" and "education".

A primeira busca de termos resultou em um total de 318 artigos. Com a aplicação do $1^{\circ}$ filtro, que limitou aos artigos de acesso completo sem especificação de temporalidade, foram obtidos 48 artigos. A aplicação do $2^{\circ}$ filtro, com leitura da introdução e conclusão reuniu um total de 39 artigos, que passaram para fase de leitura integral. Nesta fase permaneceram somente os artigos relacionados diretamente ou indiretamente com o segmento educacional, incluindo estudos relacionados às escolas e universidades, formação de professores e práticas pedagógicas. Deste montante, 23 foram selecionados para compor este estudo.

Tabela 1 - Strings de busca e ocorrências por base

\begin{tabular}{|c|c|c|c|}
\hline \multirow{2}{*}{ Especificidades } & \multicolumn{2}{|c|}{ Base de Dados } & \multirow{2}{*}{ Total } \\
\hline & Scopus & Web of Science & \\
\hline $\begin{array}{l}\text { Strings "communities of practice" } \\
\text { AND "innovation" AND "education" }\end{array}$ & 265 & 53 & 318 \\
\hline Aplicação do 1 filtro & 31 & 17 & 48 \\
\hline Aplicação do 2 filtro & 18 & 12 & 39 \\
\hline Total final incluído e analisado & 13 & 10 & 23 \\
\hline
\end{tabular}

Para a análise dos artigos escolhidos foram empregados inicialmente uma comparação considerando cinco critérios estabelecidos: a) segmento educacional em que foi aplicado: educação infantil, fundamental e médio, superior ou setorial (referindo-se ao segmento em sua totalidade); b) abordagem do artigo (qualitativa ou quantitativa); c) estratégia de investigação (estudo de caso, multicaso, pesquisa-ação, revisão bibliográfica, 
pesquisa fenomenológica); d) público envolvido no estudo; e) domínio e f) contribuições para a inovação. Posteriormente utilizou-se a análise temática (BRAUN; CLARKE, 2008) para organizar os dados para a apresentação dos resultados, conforme se explicita na sequência.

\section{RESULTADOS}

Conforme dados levantados, observou-se uma predominância dos estudos qualitativos (Gráfico 1) e empíricos o que pode ser justificado pela natureza do próprio tema, que sugere para análise abordagens que envolvam o conteúdo, a narrativa e a observação. A estratégia de investigação predominante foi o estudo de caso e multicaso, com utilização em 17 dos 23 artigos (Gráfico 2).

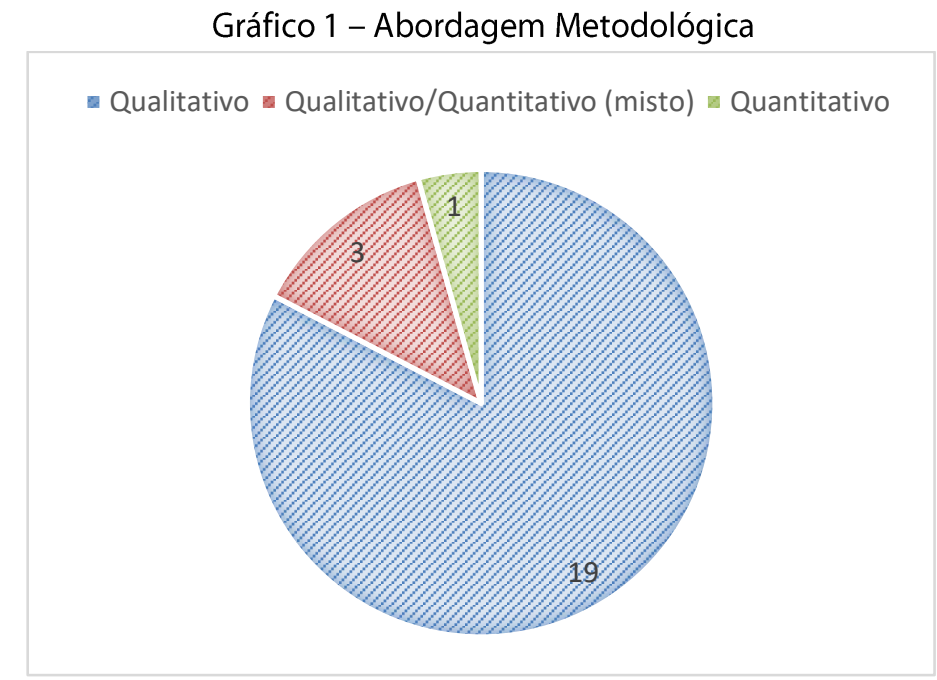

Fonte: Elaborado pelos autores (2020).

Gráfico 2 - Abordagem Metodológica

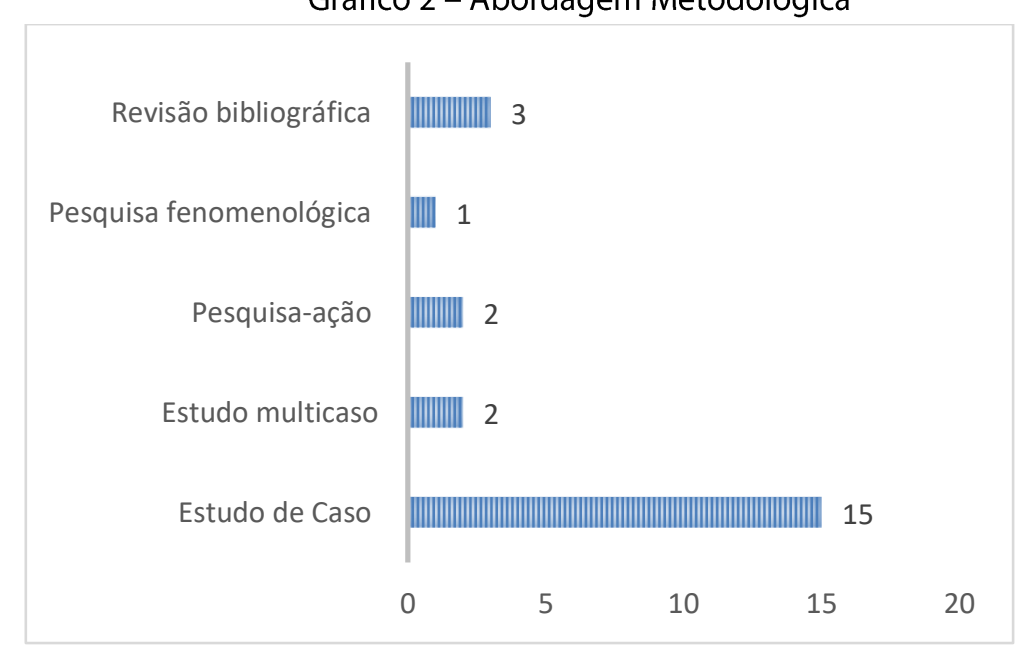

Fonte: Elaborado pelos autores (2020).

O segmento educacional (Gráfico 3) que apresenta maior número de trabalhos publicados dentro da temática proposta por este estudo é o da educação superior e pós-graduação, com predominância no número de publicações (73\%). 
Gráfico 3 - Segmento Educacional

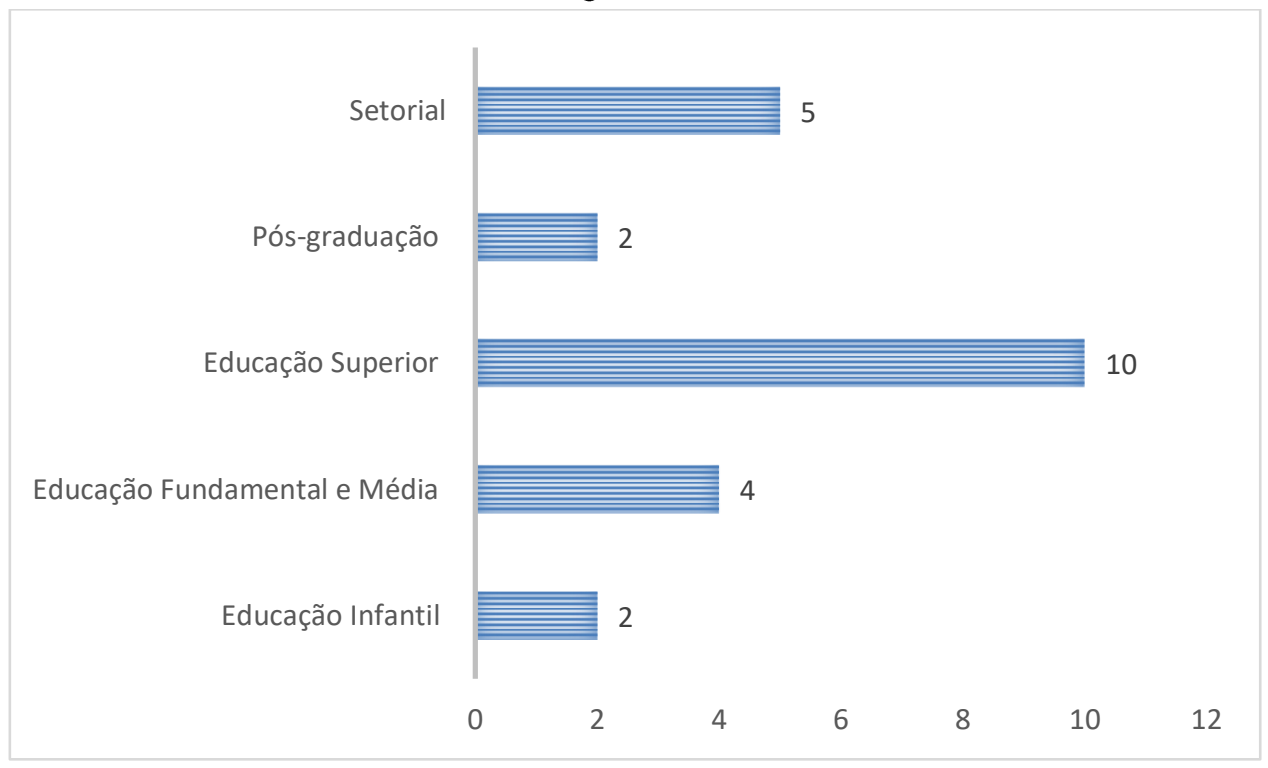

Fonte: Elaborado pelos autores (2020).

O público-alvo foco do estudo mostrou-se heterogêneo (Gráfico 4). De maneira geral, nos artigos analisados as CoPs têm aplicação maior no âmbito interno do setor educacional, ou seja, envolve principalmente seus profissionais atuantes: professores, tutores, pedagogos, designers, instrutores e gestores. Entretanto, ressalta-se que 39\% dos artigos envolvem exclusivamente os professores, instrutores ou tutores. Quando somado com os estudos que envolveram os profissionais de educação, incluindo, professores, tutores, designers, gestores e pedagogos, este número passa para 48\%. Em um dos artigos, o público envolvido são os profissionais da saúde, pois apresenta como objeto de análise centro médico mantido pela universidade. Em quatro dos artigos levantados o público-alvo eram os estudantes.

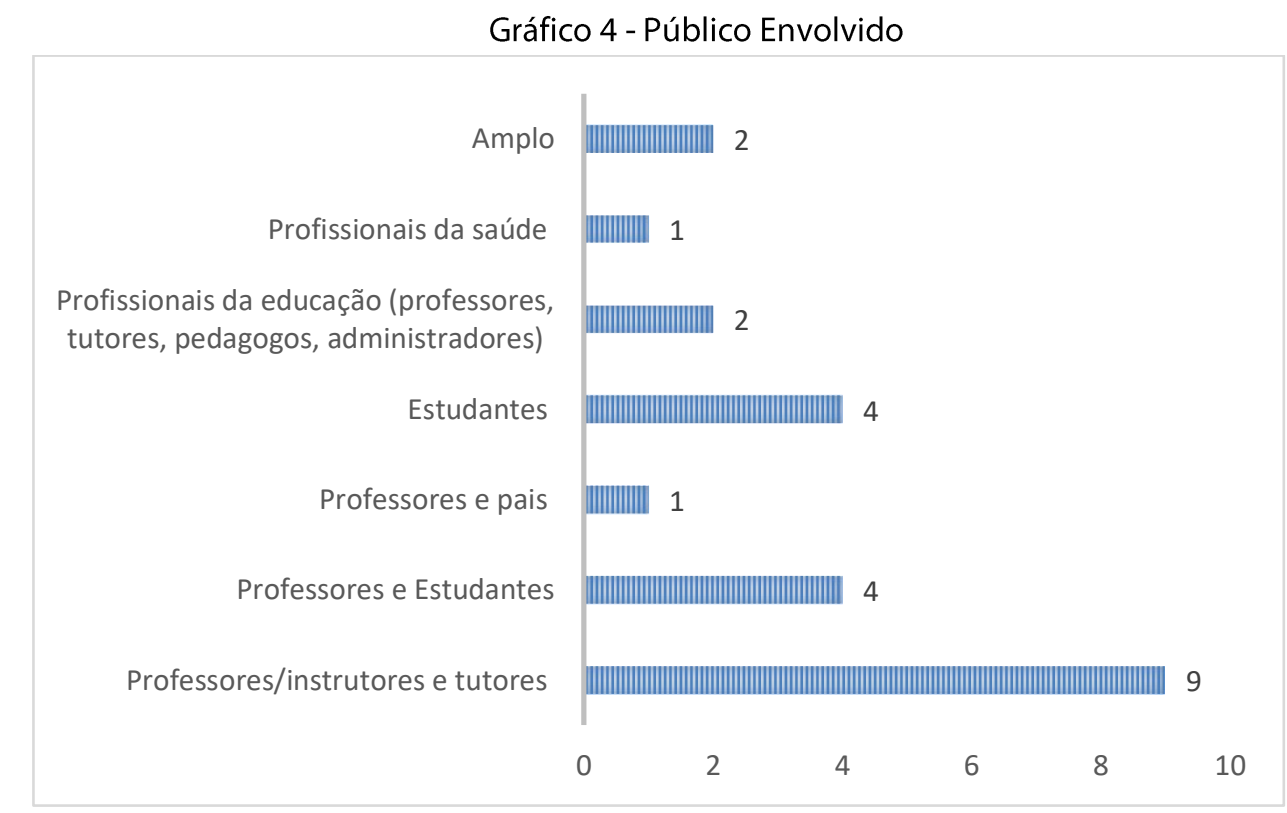

Fonte: Fonte: Elaborado pelos autores (2020).

Quanto à temporalidade (Gráfico 5), mesmo não havendo limitação de tempo nas buscas, os artigos mais antigos relacionados às palavras-chaves "communities of practice" and "innovation" and "education" surgiram em 2004, o que pode estar relacionado à aplicação e proliferação das tecnologias de informação e 
comunicação na educação, a disseminação da educação a distância e aos estudos recentes de inovação no setor educacional.

\section{Gráfico 5 - Análise da Temporalidade dos Artigos}

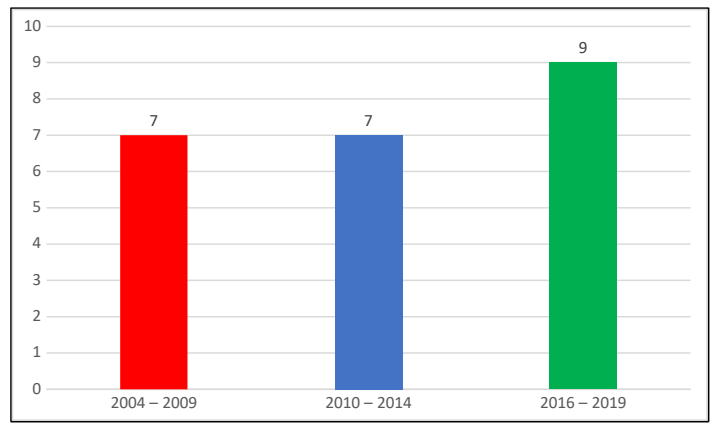

Fonte: Elaborado pelos autores (2020).

No Quadro 1, apresenta-se uma compilação dos artigos, com demonstração do objetivo de pesquisa, periódico de publicação e autores e seu país de procedência. Considerando o país de procedência dos autores, $26 \%$ dos estudos foram provenientes do Reino Unido. Os demais artigos foram originados em países diversos Observou-se que não houve registro de publicação advinda da América do Sul, contudo em um dos estudos foi analisada uma experiência brasileira (OKADA; SHERBORNE, 2018).

Quadro 1 - Análise dos artigos conforme origem, objetivo e ano

\begin{tabular}{|c|c|c|c|c|c|c|}
\hline $\mathbf{N}^{\circ}$ & Título & Autores & Periódico & Ano & Objeto de Estudo & País \\
\hline 1 & $\begin{array}{l}\text { Online professional } \\
\text { development: lessons from the } \\
\text { field }\end{array}$ & $\begin{array}{l}\text { Vrasidas e } \\
\text { Zembylas (2004) }\end{array}$ & $\begin{array}{l}\text { Education + } \\
\text { Trainning }\end{array}$ & 2004 & $\begin{array}{l}\text { Discutir as lições aprendidas com a aplicação } \\
\text { de um quadro teórico para o } \\
\text { desenvolvimento profissional dos } \\
\text { professores dos programas Teaching and } \\
\text { Learning Online (TLO) e STAR-online, } \\
\text { baseado em três áreas teóricas inter- } \\
\text { relacionadas: construtivismo, aprendizagem } \\
\text { situada e distribuída e comunidades de } \\
\text { prática on-line. }\end{array}$ & Chipre \\
\hline 2 & $\begin{array}{l}\text { New model, new strategies: } \\
\text { instructional design for } \\
\text { building online wisdom } \\
\text { communities }\end{array}$ & $\begin{array}{l}\text { Gunawardena et } \\
\text { al. (2006) }\end{array}$ & $\begin{array}{c}\text { Distance } \\
\text { Education, }\end{array}$ & 2006 & $\begin{array}{l}\text { Discutir e avaliar o desenvolvimento e } \\
\text { aplicação do modelo de design instrucional } \\
\text { WisCom em um curso de pós-graduação on- } \\
\text { line sobre o tema da educação a distância. }\end{array}$ & $\begin{array}{l}\text { Estados } \\
\text { Unidos }\end{array}$ \\
\hline 3 & $\begin{array}{l}\text { Affirming plural belonging: } \\
\text { building on students' family- } \\
\text { based cultural and linguistic } \\
\text { capital through multiliteracies } \\
\text { pedagogy }\end{array}$ & $\begin{array}{l}\text { Taylor et al. } \\
(2008)\end{array}$ & $\begin{array}{l}\text { Journal of Early } \\
\text { Childhood } \\
\text { Literacy }\end{array}$ & 2008 & $\begin{array}{l}\text { Documentar práticas de ensino e } \\
\text { aprendizagem na alfabetização. A CoP figura } \\
\text { no artigo enquanto uma interação dinâmica } \\
\text { de uma concepção de alfabetização que } \\
\text { considera e valoriza a identidade e cultura de } \\
\text { diferentes etnias ou de alunos que integram } \\
\text { minorias de linguagem. }\end{array}$ & Canadá \\
\hline 4 & $\begin{array}{l}\text { Building on Wenger: } \\
\text { communities of practice in } \\
\text { nursing }\end{array}$ & $\begin{array}{l}\text { Andrew, Tolson e } \\
\text { Ferguson (2008) }\end{array}$ & $\begin{array}{l}\text { Nurse } \\
\text { Education } \\
\text { Today }\end{array}$ & 2008 & $\begin{array}{l}\text { Analisar o conceito de comunidades, com } \\
\text { referência à estrutura CoP de Lave e Wenger } \\
\text { (1991) e debater seu potencial de aplicação } \\
\text { na enfermagem para o aprimoramento de } \\
\text { redes profissionais e educacionais. }\end{array}$ & Espanha \\
\hline 5 & $\begin{array}{l}\text { Social justice, pedagogy and } \\
\text { multiliteracies: developing } \\
\text { communities of practice for } \\
\text { teacher education }\end{array}$ & $\begin{array}{l}\text { Cumming-Potvin } \\
(2009)\end{array}$ & $\begin{array}{l}\text { Australian } \\
\text { Journal of } \\
\text { Teacher } \\
\text { Education }\end{array}$ & 2009 & $\begin{array}{l}\text { Investigar como professores em formação e } \\
\text { que atuam com alfabetização de crianças } \\
\text { desenvolvem interações em CoP para se } \\
\text { tornarem profissionais. }\end{array}$ & Austrália \\
\hline
\end{tabular}




\begin{tabular}{|c|c|c|c|c|c|c|}
\hline Q6 & $\begin{array}{l}\text { An exploration of the assessment } \\
\text { experiences of new academics as } \\
\text { they engage with a community of } \\
\text { practice in higher education }\end{array}$ & $\begin{array}{l}\text { Garrow e Tawse } \\
(2009)\end{array}$ & $\begin{array}{l}\text { Nurse Education } \\
\text { Today }\end{array}$ & 2009 & $\begin{array}{l}\text { Desenvolver uma pesquisa fenomenológica, a fim } \\
\text { de explorar como novos acadêmicos foram } \\
\text { introduzidos no processo de avaliação em um } \\
\text { contexto de ensino superior. }\end{array}$ & $\begin{array}{l}\text { Reino } \\
\text { Unido }\end{array}$ \\
\hline 7 & $\begin{array}{l}\text { Improving learning in the clinical } \\
\text { nursing environment: perceptions } \\
\text { of sênior Australian bachelor of } \\
\text { nursing students }\end{array}$ & $\begin{array}{l}\text { Smedley e Morey } \\
\text { (2009) }\end{array}$ & $\begin{array}{l}\text { Journal of Research } \\
\text { in Nursing }\end{array}$ & 2009 & $\begin{array}{l}\text { Investigar as percepçöes dos estudantes de } \\
\text { enfermagem, quanto ao ambiente de } \\
\text { aprendizagem clínica. }\end{array}$ & Austrália \\
\hline 8 & $\begin{array}{l}\text { Communities of practice of e- } \\
\text { learning, an innovative learning } \\
\text { space for e-learning actors. }\end{array}$ & $\begin{array}{l}\text { Chikhe } \\
\text { Berkani(2010) }\end{array}$ & $\begin{array}{l}\text { Procedia Social and } \\
\text { Behavioral Sciences }\end{array}$ & 2010 & $\begin{array}{l}\text { Mostrar o potencial de aprendizagem social no } \\
\text { domínio do e-learning, através CoPs de e-learning. }\end{array}$ & $\begin{array}{l}\text { Arábia } \\
\text { Saudita e } \\
\text { Argélia }\end{array}$ \\
\hline 9 & $\begin{array}{l}\text { Innovation with change: } \\
\text { developing a community of } \\
\text { practice to help teachers move } \\
\text { beyond the 'honeymoon' of } \\
\text { pedagogical renovation }\end{array}$ & $\begin{array}{l}\text { Goodyear e } \\
\text { Casey (2013) }\end{array}$ & $\begin{array}{l}\text { Physical Education } \\
\text { and Sport Pedagogy }\end{array}$ & 2013 & $\begin{array}{l}\text { Explorar como as comunidades de prática } \\
\text { emergem, desenvolvem e apoiam a inovação que } \\
\text { resulta em mudança pedagógica. }\end{array}$ & $\begin{array}{l}\text { Reino } \\
\text { Unido }\end{array}$ \\
\hline 10 & \begin{tabular}{|l} 
Conceptual Model of Successful \\
Educational Online Community of \\
Practice for Kingdom of Saudi \\
Arabia
\end{tabular} & $\begin{array}{l}\text { Al-Shahrani e } \\
\text { Mohammad } \\
(2014)\end{array}$ & iJET & 2014 & $\begin{array}{l}\text { Analisar o sucesso da implementação da } \\
\text { Comunidade de Prática na educação da Arábia } \\
\text { Saudita. }\end{array}$ & $\begin{array}{l}\text { Arábia } \\
\text { Saudita }\end{array}$ \\
\hline 11 & $\begin{array}{l}\text { Prácticas educativas abiertas y } \\
\text { apropiación tecnológica: el caso de } \\
\text { la Comunidad Latinoamericana } \\
\text { Abierta y Regional de Investigación } \\
\text { Social y Educativa (CLARISE) }\end{array}$ & $\begin{array}{l}\text { Franco, Ramírez e } \\
\text { Montoya (2014) }\end{array}$ & $\begin{array}{l}\text { Revista de } \\
\text { Universidad y } \\
\text { Sociedad del } \\
\text { Conocimiento }\end{array}$ & 2014 & $\begin{array}{l}\text { Analisar o estado das práticas educativas abertas } \\
\text { nas Instituiçöes que fazem parte do American } \\
\text { Community Open Latin Regional de Pesquisas } \\
\text { Educacionais (CLARISE) Social. }\end{array}$ & México \\
\hline 12 & $\begin{array}{l}\text { Riding the wave of BYOD: } \\
\text { developing a framework for } \\
\text { creative pedagogies }\end{array}$ & Cochrane et al. & $\begin{array}{l}\text { Research in Learning } \\
\text { Technology }\end{array}$ & 2014 & $\begin{array}{l}\text { Desenvolver uma metodologia de pedagogia } \\
\text { criativa baseada no "bring your own device } \\
\text { (BYOD)", utilizando de recursos de mídias sociais e } \\
\text { CoP. }\end{array}$ & $\begin{array}{l}\text { Nova } \\
\text { Zelândia e } \\
\text { Reino } \\
\text { Unido }\end{array}$ \\
\hline 13 & $\begin{array}{l}\text { Tweet me, message me, like me: } \\
\text { using social media to facilitate } \\
\text { pedagogicalsocial media to } \\
\text { facilitate pedagogical change } \\
\text { within an emerging community of } \\
\text { practice. }\end{array}$ & $\begin{array}{l}\text { Goodyear, } \\
\text { Caseya e Kirka } \\
\text { (2014) }\end{array}$ & $\begin{array}{l}\text { Sport, Education and } \\
\text { Society, }\end{array}$ & 2014 & $\begin{array}{l}\text { Explorar como a mídia social funciona como um } \\
\text { espaço comunicativo entre professores, externo ao } \\
\text { local físico de uma CoP. }\end{array}$ & $\begin{array}{l}\text { Reino } \\
\text { Unido }\end{array}$ \\
\hline 14 & $\begin{array}{l}\text { Between the real school and the } \\
\text { ideal school: another step in } \\
\text { building a teaching identity }\end{array}$ & $\begin{array}{l}\text { Correa, Martínez- } \\
\text { Arbelaiz e } \\
\text { Gutierrez (2014) }\end{array}$ & $\begin{array}{l}\text { Journal Educational } \\
\text { Review }\end{array}$ & 2014 & $\begin{array}{l}\text { Descrever, analisar e interpretar as ideias, } \\
\text { representações e experiências que constroem uma } \\
\text { identidade profissional de ensino. }\end{array}$ & Espanha \\
\hline 15 & \begin{tabular}{|l} 
Preparing Teachers for the "Schools \\
That Technology Built"
\end{tabular} & $\begin{array}{l}\text { Davis e Roblyer } \\
\text { (2015) }\end{array}$ & $\begin{array}{l}\text { Journal of Research } \\
\text { on Technology in } \\
\text { Education }\end{array}$ & 2015 & $\begin{array}{l}\text { Descrever o modelo da Universidade Estadual de } \\
\text { lowa de formação de professores para atuação no } \\
\text { ensino fundamental à distância. }\end{array}$ & $\begin{array}{l}\text { Estados } \\
\text { Unidos }\end{array}$ \\
\hline 16 & $\begin{array}{l}\text { An analysis of STEM/STEAM teacher } \\
\text { education in Korea with a case } \\
\text { study of two schools from a } \\
\text { community of practice perspective }\end{array}$ & $\begin{array}{l}\text { Jho, Hong e Song } \\
(2016)\end{array}$ & $\begin{array}{l}\text { Eurasia Journal of } \\
\text { Mathematics, } \\
\text { Science \& } \\
\text { Technology } \\
\text { Education }\end{array}$ & 2016 & $\begin{array}{l}\text { Investigar como os professores do programa } \\
\text { educacional STEAM tem implementado a } \\
\text { metodologia, sob as lentes da CP. }\end{array}$ & Coréia \\
\hline 17 & $\begin{array}{l}\text { Beyond coursework: developing } \\
\text { communities in an online program } \\
\text { of study }\end{array}$ & Oakman (2016) & $\begin{array}{c}\text { Journal of } \\
\text { Information } \\
\text { Technology } \\
\text { Education: } \\
\text { Innovations in } \\
\text { Practice } \\
\end{array}$ & 2016 & $\begin{array}{l}\text { Investigar o valor das interaçôes em um curso de } \\
\text { pós-graduação on-line para suportar o } \\
\text { desenvolvimento de comunidades de prática. }\end{array}$ & Austrália \\
\hline 18 & $\begin{array}{l}\text { The Health Professions Education } \\
\text { Pathway: Preparing Students, } \\
\text { Residents, and } \\
\text { Fellows to Become Future } \\
\text { Educators }\end{array}$ & Chen et al (2017) & $\begin{array}{c}\text { Teaching and } \\
\text { Learning In Medicine }\end{array}$ & 2017 & $\begin{array}{l}\text { Analisar os resultados do programa para formação } \\
\text { dos futuros educadores da área de saúde. }\end{array}$ & $\begin{array}{l}\text { Estados } \\
\text { Unidos }\end{array}$ \\
\hline
\end{tabular}




\begin{tabular}{|c|c|c|c|c|c|c|}
\hline 19 & $\begin{array}{l}\text { The Interdisciplinary Use of Blogs } \\
\text { and Online Communities in Teacher } \\
\text { Education }\end{array}$ & $\begin{array}{l}\text { Caldwell e } \\
\text { Heaton (2016) }\end{array}$ & $\begin{array}{l}\text { International Journal of } \\
\text { Information and } \\
\text { Learning Technology }\end{array}$ & 2016 & \begin{tabular}{|l} 
Analisar o conteúdo multimodal de cinco blogs e \\
comunidades do Google + , seus fatores limitantes \\
e de sucesso, tendo como foco as temáticas CoP, \\
aprendizagem reflexiva e uso da tecnologia.
\end{tabular} & $\begin{array}{l}\text { Reino } \\
\text { Unido }\end{array}$ \\
\hline 20 & $\begin{array}{l}\text { TELFest: an approach to } \\
\text { encouraging the adoption of } \\
\text { educational Technologies }\end{array}$ & Latif (2017) & $\begin{array}{l}\text { Research in Learning } \\
\text { Technology }\end{array}$ & 2017 & \begin{tabular}{|l|} 
Descrever como o evento TELFest (Technology \\
Enhanced Learning Festival) impacta na prática \\
docente e nos acadêmicos por meio de criação de \\
uma CoP voltada à inovação educacional.
\end{tabular} & Inglaterra \\
\hline 21 & $\begin{array}{l}\text { Social Media Scholarship and } \\
\text { Alternative } \\
\text { Metrics for Academic Promotion } \\
\text { and Tenure }\end{array}$ & $\begin{array}{l}\text { Cabrera, Roye } \\
\text { Chisolm (2017) }\end{array}$ & $\begin{array}{l}\text { American College of } \\
\text { Radiology }\end{array}$ & 2017 & $\begin{array}{l}\text { Delinear novas estratégias e ferramentas para a } \\
\text { avaliação de divulgação e impacto de obras } \\
\text { médicas acadêmicas. }\end{array}$ & $\begin{array}{l}\text { Estados } \\
\text { Unidos }\end{array}$ \\
\hline 22 & $\begin{array}{l}\text { Equipping the Next Generation for } \\
\text { Responsible Research and } \\
\text { Innovation with Open Educational } \\
\text { Resources, Open Courses, Open } \\
\text { Communities and Open Schooling: } \\
\text { An Impact Case Study in Brazil } \\
\end{array}$ & $\begin{array}{l}\text { Okada e } \\
\text { Sherborne } \\
\text { (2018) }\end{array}$ & $\begin{array}{l}\text { Journal of } \\
\text { Interactivemedia in } \\
\text { Education }\end{array}$ & 2018 & $\begin{array}{l}\text { Analisar o projeto ENGAGE que se concentra em } \\
\text { um modelo integrado que combina REA, MOOC, } \\
\text { CoP e Escola Aberta para promover a educação } \\
\text { aberta e habilidades de investigação para } \\
\text { Pesquisa e Inovação Responsáveis (RRI). }\end{array}$ & $\begin{array}{l}\text { Reino } \\
\text { Unido }\end{array}$ \\
\hline 23 & $\begin{array}{l}\text { Nurturing innovation and creativity } \\
\text { in educational practice: principles } \\
\text { for supporting faculty peer learning } \\
\text { through campus design }\end{array}$ & $\begin{array}{l}\text { Winks, Green e } \\
\text { Dyer (2019) }\end{array}$ & Higher Education & 2019 & $\begin{array}{l}\text { Examinar as maneiras como os espaços do } \\
\text { campus de uma universidade do Reino Unido são } \\
\text { utilizados pelos funcionários para o aprendizado } \\
\text { entre pares e inovação e criatividade na prática } \\
\text { educacional. }\end{array}$ & $\begin{array}{l}\text { Reino } \\
\text { Unido }\end{array}$ \\
\hline
\end{tabular}

Fonte: Elaborado pelos autores (2020).

\section{ANÁLISE}

Sob uma definição ampla, as CoPs aparecem como grupos de pessoas que se relacionam dinamicamente para conexão de práticas e geração de conhecimentos, sejam explícitos ou tácitos. Nos artigos analisados predominam a teoria de Lave e Wenger (1991) e Wenger (2012), o que pode estar associado ao fato do termo ter sido introduzido por estes autores.

Três dos artigos pesquisados são teóricos, com estratégia de investigação baseada em revisão bibliográfica. Nessa linha, Andrew, Tolson e Ferguson (2008) enfocam os estudos no setor de enfermagem e destacam a teoria de Wenger e a sua aplicação no setor, enquanto o estudo de Cabrera, Roy e Chisolm (2018) trata das métricas de obras médicas acadêmicas.

Em artigos empíricos observou-se que nem sempre CoPs são de adesão voluntária ou livre criação. Nos estudos de Al-Shahrani e Mohammad (2014), Davis e Roblyer (2005), Goodyear e Casey (2013), Gunawardena et al. (2006), Jho, Hong e Song (2016), Okada e Sherborne (2018), Vrasidas e Zembylas (2004), houve clara evidência de apoio ou estímulo institucional e, até mesmo, a presença de mediadores ou pessoas chaves, tal como descrito na pesquisa de Goodyear e Casey (2013). Tal configuração é prevista por Wenger e Snyder (2000) e Wenger (2015). Os artigos citados evidenciaram empiricamente a utilização de CoPs, sejam para apoiar a implementação de novos programas ou projetos como também para promoverem deliberadamente a inovação. Nestes estudos as CoPs foram utilizadas tanto como estratégia quanto método para implantação de inovações de práticas pedagógicas.

O termo "CoP" foi empregado também sob uma ótica conceitual para elaboração ou explicação de modelos e frameworks, apropriando-se dos conceitos exposto por Lave e Wenger (1991) e Wenger (2012). Na perspectiva conceitual foi abordada para analisar relações entre pares, promover entendimento sobre o processo de aprendizagem colaborativo, aprendizagem situada, acesso à participação periférica legítima e a construção de identidade profissional, relacionando com a inovação. Isto foi percebido nos artigos de Chen et al. (2017), Correa, Martínez-Arbelaiz e Gutierrez (2014), Cumming-Potvin (2009), Smedley e Morey (2009) e Taylor et al. (2008).

O público envolvido nos estudos levantados incluíram professores e demais profissionais da educação, pesquisadores, especialistas e estudantes, confirmando o emprego múltiplo na educação apontado por Wenger (2015). Contudo, em um número significativo de artigos as CoPs foram empregadas no âmbito interno junto a professores, instrutores, tutores, pesquisadores e especialistas visando a apoio, estímulo ou suporte para implementação de mudanças pedagógicas, evidenciando os esforços do setor de educação para 
a redução dos hiatos entre a prática e as novas demandas da sociedade. Dos 23 artigos pesquisados, cinco estiveram relacionados à formação de educadores, os quais estão expostos no Quadro 2 e são descritos na sequência.

Quadro 2 - Artigos com foco na formação dos educadores

\begin{tabular}{|l|l|l|l|}
\hline \multicolumn{1}{|c|}{ Título } & \multicolumn{1}{|c|}{ Referência } & Abordagem & Estratégia de investigação \\
\hline $\begin{array}{l}\text { Online professional development: lessons } \\
\text { from the field }\end{array}$ & Vrasidas e Zembylas (2004) & Qualitativa & Estudo de caso \\
\hline $\begin{array}{l}\text { Social justice, pedagogy and multiliteracies: } \\
\text { developing communities of practice for } \\
\text { teacher education }\end{array}$ & Cumming-Potvin (2009) & Qualitativa & Estudo de caso \\
\hline $\begin{array}{l}\text { Innovation with change: developing a } \\
\text { community of practice to help teachers move } \\
\text { beyond the 'honeymoon' of pedagogical } \\
\text { renovation }\end{array}$ & Goodyear e Casey (2013) & Qualitativa & Pesquisa-ação \\
\hline $\begin{array}{l}\text { Preparing teacher that technologies built } \\
\text { An analysis of STEM/STEAM teacher } \\
\text { education in Korea with a case study of two } \\
\text { schools from a community of practice } \\
\text { perspective }\end{array}$ & Davis e Roblyer (2015) & Qualitativa & Estudo de caso \\
\hline
\end{tabular}

Fonte: Elaborado pelos autores (2020).

Vrasidas e Zembylas (2004) publicaram um estudo a respeito do desenvolvimento profissional dos professores e dos tutores para o ensino à distância, envolvendo três escopos: construtivismo, aprendizagem situada e distribuída, e comunidades de prática. Entre as experiências retratadas está a Star-Online, uma CoP virtual que proporciona aos participantes um ambiente interativo e com diversidade cultural. A inovação é tratada no artigo enquanto um compromisso que se concretiza pela existência dos projetos mencionados no estudo, incluindo o Star-Online.

O artigo de Cumming-Potvin (2009) apresentou como enfoque a inovação na formação contínua de professores que atuam com alfabetização de crianças. O autor desenvolve os conceitos de justiça social, alfabetização e pedagogia a partir de uma perspectiva de aprendizagem baseada na interação social. Apoiando-se na teoria sociocultural de Vigostki e nos estudos de Jean Lave e Ettiene Wenger, o autor investiga como os professores em formação desenvolvem entendimentos através da interação em comunidades complexas de prática para se tornarem professores de alfabetização.

Goodyear e Casey (2013) desenvolveram uma pesquisa-ação junto a seis professores do departamento de educação física de uma escola de ensino fundamental e médio da Inglaterra. Este artigo demonstra que a intenção de criação de CoP esteve deliberadamente voltada à inovação de práticas pedagógicas. A CoP é apresentada tanto como estratégia para agregar os profissionais quanto como um método. Os autores concluíram que, embora Lave e Wenger (1991) informem a necessidade de a comunidade surgir naturalmente, a pessoa-chave fez diferença para que os professores percebessem os efeitos da aprendizagem cooperativa estimulando-os à inovação de suas práticas. Assim, na percepção dos autores do estudo, a inovação também esteve centrada no modelo de aprendizagem cooperativa.

Davis e Roblyer (2015) descreveram o programa da Universidade Estadual de lowa (Estados Unidos) de formação de professores para atuação no ensino fundamental a distância, em relação a sua eficácia, métodos de implantação e disseminação através de CoP de abrangência nacional. O programa denominado The Teacher Education Goes Into Virtual Schooling (TEGIVS), prepara conselheiros, professores, designers e assistentes e tem como uma das ações a criação de uma CoP voltada à formação de professores, visando a interação e aprimoramento de práticas. Embora o artigo não tivesse o intuito de descrever os resultados específicos alcançados com a CoP, os autores finalizaram reforçando que as inovações no ensino fundamental e médio não ocorrem sem uma inovação na formação dos professores. 
Em outra experiência com formação de professores, os autores Jho, Hong e Song (2016) investigaram como os professores atuantes no programa educacional coreano STEAM (Science, Technology, Engineering, Arts and Mathematics), tem implementado a metodologia, na perspectiva da CoP. Como uma das estratégias do programa foram estimuladas a criação de CoPs, denominadas de STEAM - Research Group of Teachers (STEAM-RGT), com o intuito de desenvolver conteúdos e estratégias de ensino em conjunto. As CoPs têm adesão voluntária, podem envolver professores de diferentes áreas, dentro da mesma escola ou de escolas diferentes, utilizar meios virtuais ou presenciais e ter apoio financeiro. Percebe-se que, na experiência relatada pelos autores, as CoPs tiveram um papel de destaque na implementação da metodologia e na inovação em si, proporcionando um ambiente de apoio para solução de problemas, criação e disseminação de conhecimentos.

A utilização das mídias sociais, Recursos Acadêmicos Abertos (REA) e utilização de dispositivos associados às CoPs também foram retratados por Caldwell e Heaton (2016), Cochrane et al. (2014), Franco, Ramírez e Montoya (2014), Goodyear, Casey e Kirk (2014) e Okada e Sherborne (2018). Isto confirma a tendência da educação aberta, corroborando com o próprio conceito de inovação aberta. Alinha-se também com as ideias de aproveitamento da conectividade e mídias sociais para engajar comunidades, compartilhar repertórios, promover aprendizagem e, até mesmo, para servir de métricas para promoção em planos de carreira acadêmica, tal como exposto por Cabrera, Roy e Chilsom (2018).

Os quatro artigos tiveram como foco mídias sociais a recursos educacionais abertos (Quadro 3).

Quadro 3 - Artigos com foco em mídias sociais e recursos educacionais abertos

\begin{tabular}{|l|l|l|c|}
\hline \multicolumn{1}{|c|}{ Título } & \multicolumn{1}{|c|}{ Referência } & Abordagem & $\begin{array}{c}\text { Estratégia de } \\
\text { investigação }\end{array}$ \\
\hline $\begin{array}{l}\text { Tweet me, message me, like me: using social media to facilitate pedagogical } \\
\text { change within an emerging community of practice }\end{array}$ & $\begin{array}{l}\text { Goodyear, Casey e } \\
\text { Kirk (2014) }\end{array}$ & Qualitativa & Pesquisa-ação \\
\hline $\begin{array}{l}\text { Riding the wave of BYOD: developing a framework for creative pedagogies } \\
\text { Cochrane et al. } \\
(2014)\end{array}$ & $\begin{array}{l}\text { Qualitativa } \\
\text { (2016) }\end{array}$ & Pesquisa-ação \\
\hline $\begin{array}{l}\text { The Interdisciplinary Use of Blogs and Online Communities in Teacher } \\
\text { Education }\end{array}$ & $\begin{array}{l}\text { Cabrera, Roy e } \\
\text { Chilsom (2018) }\end{array}$ & Qualitativa & Estudo multicaso \\
\hline $\begin{array}{l}\text { Social Media Scholarship and Alternative } \\
\text { Metrics for Academic Promotion } \\
\text { and Tenure }\end{array}$ & $\begin{array}{c}\text { Revisão } \\
\text { Bibliográfica }\end{array}$ \\
\hline
\end{tabular}

Fonte: Elaborado pelos autores (2020).

Goodyear, Casey e Kirk (2014) analisaram como a mídia social funciona como um espaço comunicativo entre professores, externo ao local físico de uma Comunidade de Prática, e que auxilia no processo de inovação. Os autores ainda inferiram que as mídias sociais atuaram como uma forma de conexão entre os professores com a finalidade de aprendizagem cooperativa, apoiando a mudança pedagógica.

Cochrane et al. (2014) pesquisaram como desenvolver uma metodologia de pedagogia criativa baseada no Bring Your Own Device (BYOD), utilizando de recursos de mídias sociais e CoP. $\mathrm{O}$ artigo descreve a implementação do projeto MoCo360, que se trata de uma CoP não financiada integrada por educadores da Nova Zelândia, Colômbia, França e Reino Unido, que pensam como explorar o potencial das mídias sociais móveis e, em particular o cinema móvel, para desenvolver colaborativamente experiências de aprendizagem nos estudantes. Neste estudo, a inovação é retratada para o desenvolvimento de práticas criativas de aprendizagem, utilizando dispositivos e mídias sociais, sendo a CoP um importante catalisador deste processo, permitindo e estimulando interação, trocas e participação ampla.

No artigo de Caldwell e Heaton (2016) as mídias sociais também estão no foco da pesquisa. O estudo analisou o conteúdo de cinco experiências educacionais no ensino superior que envolveram blogs e Comunidades de Prática criadas no Google + . Os autores identificaram os fatores limitantes e de sucesso no reforço da aprendizagem, tendo como foco as temáticas CoP, a aprendizagem reflexiva e o uso da tecnologia. Observou-se que a inovação é tratada no artigo com relação à implementação de ações práticas. Para os autores, os blogs constituem-se de um espaço social de compartilhamento de conteúdo, com aplicação 
possível também para a criação de comunidade de aprendizagem, colaboração ativa, desenvolvimento de sentimento de propriedade e de uma postura reflexiva pelos alunos.

A respeito de metodologias ativas e criação de ambientes interativos e reflexivos, cinco artigos têm como foco os estudantes e suas relações (Quadro 4).

Quadro 4 - CoPs com foco nos estudantes e suas relações

\begin{tabular}{|l|l|l||l|}
\hline \multicolumn{1}{|c|}{ Título } & \multicolumn{1}{|c|}{ Referência } & Abordagem & $\begin{array}{c}\text { Estratégia de } \\
\text { investigação }\end{array}$ \\
\hline $\begin{array}{l}\text { New model, new strategies: instructional design for building online } \\
\text { wisdom communities }\end{array}$ & Gunawardena et al.(2006) & Qualitativa & Estudo de caso \\
\hline $\begin{array}{l}\text { Improving learning in the clinical nursing environment: perceptions of } \\
\text { sênior Australian bachelor of nursing students }\end{array}$ & Smedley e Morey (2009) & Quantitativo & Estudo de caso \\
\hline $\begin{array}{l}\text { Between the real school and the ideal school: another step in building } \\
\text { a teaching identity }\end{array}$ & $\begin{array}{l}\text { Correa, Martínez-Arbelaiz e } \\
\text { Gutierrez (2014) }\end{array}$ & Qualitativa & Estudo de caso \\
\hline $\begin{array}{l}\text { Beyond coursework: developing communities in an online program of of } \\
\text { study }\end{array}$ & Oakman (2016) & Qualitativa & Estudo de caso \\
\hline $\begin{array}{l}\text { The Health Professions Education Pathway: Preparing Students, } \\
\text { Residents, and } \\
\text { Fellows to Become Future Educators }\end{array}$ & Chen et al. (2017) & Qualitativa & Estudo de caso \\
\hline
\end{tabular}

Fonte: Elaborado pela autores (2020).

Gunawardena et al. (2006) discutiram e avaliaram o desenvolvimento e aplicação do design instrucional WisCom em um curso de pós-graduação on-line dos Estados Unidos. O modelo, estruturado na perspectiva socioconstrutivista, sociocultural e nos princípios da COP e do EAD, combina as dimensões cognitivas, afetivas e sociais de aprender e criar um ambiente de reflexão, partilha e voltado à inovação do conhecimento. Conforme descrição do framework, o modelo se baseia em um ambiente centrado na aprendizagem social que valoriza a interação entre alunos e destes com os professores e instrutores. Também se apoia na existência de mentorias, que auxiliam os membros mais novos a se incluírem na comunidade e na inovação do conhecimento. Embora o artigo não especifique ou aprofunde o funcionamento da CoP traz em tela os constructos do framework criado para o WisCom e como este se apoia nos conceitos associados à Comunidade de Prática e na aprendizagem colaborativa em um ambiente virtual.

Em um dos únicos artigos de abordagem exclusivamente quantitativa, Smedley e Morey (2009) desenvolveram um estudo na Avondale College na Austrália, envolvendo os futuros bacharéis de enfermagem. Os estudos de Lave e Wenger (1991), com enfoque nos conceitos de Comunidade de Prática e de aprendizagem situada foram enfatizados na publicação. Smedley e Morey (2009) apontaram o espaço clínico para estudantes de enfermagem como uma CoP, que necessita de cooperação, apoio, compreensão, unidade e inclusão. Práticas pedagógicas inovadoras, uma das categorias abordadas no instrumento de coleta, não foi percebida pelos estudantes em suas experiências de estágio clínico, indicando a necessidade de melhorias. Outro carência levantada foi a maior preocupação por parte dos professores e demais membros do corpo clínico pelo bem-estar do aluno e o desenvolvimento de relações positivas, permitindo que estes se tornem membros valiosos na CoP e afetando positivamente a percepção sobre o trabalho e a própria aprendizagem.

Oakman (2016) analisou as interações dos alunos em um curso de pós-graduação on-line sob a ótica do desenvolvimento de uma CoP e seus efeitos. $\mathrm{O}$ estudo envolveu 25 alunos de um programa de pósgraduação de Ergonomia, Segurança e Saúde Ocupacional do Centre for Ergonomics and Human Factors da Faculdade de Ciências da Saúde da Austrália. Apoiado nos estudos de Jean Lave e Etienne Wenger, Oakman sustenta que os princípios de design educacional de pós-graduação em EaD deveriam ir além do currículo do curso, para valorizar o repertório e a experiência dos partícipes em seus diversos campos e incorporar pontos significativos de interação, por meio do emprego de tecnologias apropriadas. Neste artigo, observou-se que a inovação não é explicitamente tratada, e aponta necessidades de inovações no ensino de pós-graduação.

Ainda no grupo de artigos que têm como enfoque os estudantes, Chen et al. (2017) e Correa, Martínez-Arbelaiz e Gutierrez (2014) trazem a CoP como espaço de construção de identidade profissional e de 
formação profissional voltada ao desenvolvimento de profissionais criativos e inovadores. Correa, MartínezArbelaiz e Gutierrez (2014) destacam a construção de identidade de futuros professores de educação infantil e concluíram que as mudanças necessárias na educação, perpassam por uma alteração na própria construção da identidade profissional. Chen et al. (2017) também retratam a construção de novas identidades profissionais ao estudarem o framework do programa Universidade da Califórnia que se baseia em CoP e prepara os estudantes da área da saúde para se tornarem futuros educadores.

Alguns artigos desta revisão (Quadro 5) abordam a CoP dentro de projetos educacionais amplos, que enfatizam de forma direta ou indireta a inovação enquanto programa de mudanças na educação. Neste grupo de artigos é possível perceber também práticas de inovação aberta na educação, retratada nos estudos de Franco, Ramírez e Montoya (2014) e Okada e Sherborne (2018).

Quadro 5 - Estudos de CoP dentro de abordagens setoriais

\begin{tabular}{|l|l|c|c|}
\hline \multicolumn{1}{|c|}{ Título } & \multicolumn{1}{|c|}{ Referência } & Abordagem & $\begin{array}{l}\text { Estratégia de } \\
\text { investigação }\end{array}$ \\
\hline $\begin{array}{l}\text { Conceptual Model of Successful Educational Online Community of Practice } \\
\text { for Kingdom of Saudi Arabia }\end{array}$ & $\begin{array}{l}\text { Al-Shahrani e } \\
\text { Mohammad (2014) }\end{array}$ & Qualitativa & $\begin{array}{c}\text { Design Science } \\
\text { Research Model (DSR) }\end{array}$ \\
\hline $\begin{array}{l}\text { Prácticas educativas abiertas y apropiación tecnológica: el caso de la } \\
\text { Comunidad Latinoamericana Abierta y Regional de Investigación Socialy } \\
\text { Educativa (CLARISE) }\end{array}$ & $\begin{array}{l}\text { Franco, Ramírez e } \\
\text { Montoya (2014) }\end{array}$ & Qualitativa & Estudo de caso \\
\hline $\begin{array}{l}\text { Equipping the Next Generation for Responsible Research and Innovation } \\
\text { with Open Educational Resources, Open Courses, Open Communities and } \\
\text { Open Schooling: An Impact Case Study in Brazil }\end{array}$ & $\begin{array}{l}\text { Okada e Sherborne } \\
\text { (2018) }\end{array}$ & Qualitativa & Estudo de caso \\
\hline
\end{tabular}

Fonte: Elaborado pela autores (2020).

Os autores Al-Shahrani e Mohammad (2014) criaram um modelo conceitual para o sucesso da implementação da CoP na educação na Arábia Saudita. Os autores reforçam que as CoPs virtuais são recursos de aprendizagem eficientes, que possibilitam ampla participação, baixo custo e facilitam a conectividade entre os membros, a transferência de conhecimento e a inovação. No modelo, os autores estabeleceram sete variáveis que afetam uma implementação bem sucedida de CoP expressas na Figura 2.

Figura 2 - Modelo conceitual de CoP de Al-Shahrani e Mohammad (2014)

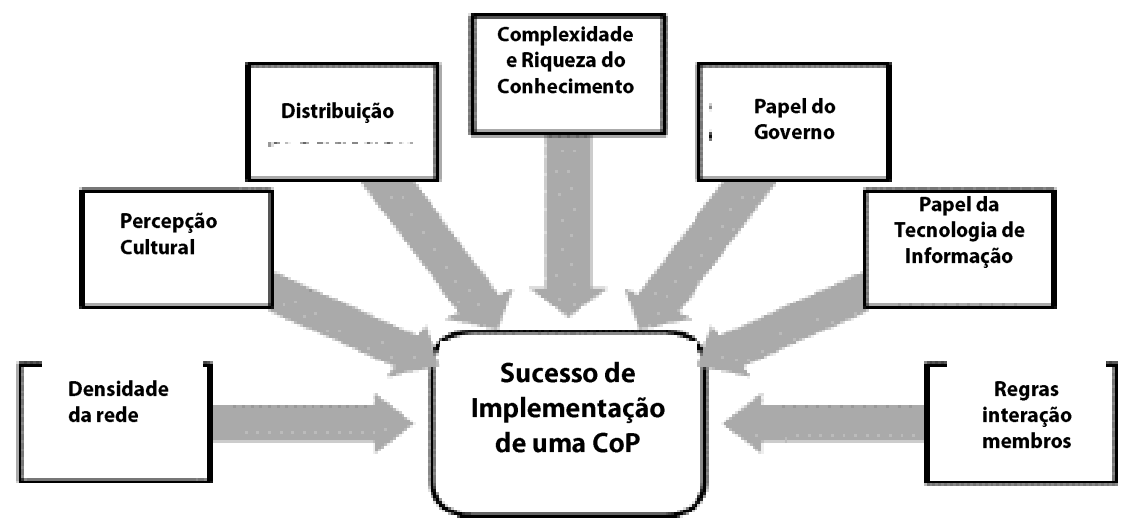

Fonte: Adaptado de Al-Shahrani e Mohammad (2014).

O estudo de Franco, Ramírez e Montoya (2014) analisou o estado das práticas educativas abertas nas instituições que fazem parte da Comunidad Latino Americana Abierta Regional de Investigación Social y Educativa (CLARISE). Essa comunidade é composta por professores e pesquisadores para a cogeração de REA que promovam inovação em métodos e estratégias de ensino. No estudo, os autores buscaram identificar 
como os REA impactaram a comunidade na melhoria dos processos educativos e como ocorre esta apropriação tecnológica.

Okada e Sherborne (2018) destacaram também os REA e analisaram como o projeto Engage, que integra REA, MOOC, CoP e escola aberta, promovem a educação aberta e habilidades de investigação para Responsible Research and Innovation (RRI). Os autores comentam que para este movimento é importante promover novas habilidades e conhecimentos para professores, a fim de que estes possam desenvolver nos alunos o interesse pela ciência e seu funcionamento e as competências para o pensamento crítico criativo. Neste caso, percebe-se que a CoP Engage foi criada deliberadamente para promover a inovação pedagógica voltada ao RRI.

Nem todos os artigos analisados retrataram a inovação de uma forma explicitamente ligada à CoP. Outro ponto observado foi o múltiplo emprego do termo. A inovação, além de ser enfoque de programas educacionais amplos expostos anteriormente, apareceu atrelada à necessidade de proporcionar experiência ativa e reflexiva do aluno, a aprendizagem colaborativa tanto de alunos quanto dos profissionais de educação, à adoção de tecnologias de informação e comunicação apropriadas ao contexto e, até mesmo, a formação de identidade profissional inovadora. Entretanto, pela análise dos artigos, observou-se maior predominância do uso de CoPs voltadas à inovação de práticas pedagógicas.

A classificação quanto ao tipo de CoP, se virtual, presencial ou mista também não foi algo explicitado em todos os artigos. Contudo, percebeu-se que nos estudos em que havia a indicação da tipologia ocorreu predominância de artigos de CoPs virtuais ou híbridas, apontando que a web e as tecnologias de informação e comunicação, tal como afirmam Correia, Paulos e Mesquita (2008), colaboram e facilitam o seu emprego, além de reduzir o distanciamento geográfico e os custos.

\section{CONSIDERAÇÕES FINAIS}

O presente trabalho analisou a utilização da CoP no setor de educação, tendo como enfoque a inovação. Os artigos analisados, provenientes de pesquisas nas bases de dados Scopus e Web of Science, apontaram que as CoPs na educação são empregadas nos mais variados contextos, domínios e níveis educacionais, que vão desde o ensino infantil à pós-graduação.

Sob uma definição ampla, as CoPs aparecem enquanto um grupo de pessoas que se relacionam dinamicamente para conexão de práticas e geração de conhecimentos, sejam explícitos ou tácitos. É predominante nos artigos analisados a teoria de Lave e Wenger (1991) e Wenger (2012), o que pode estar associado ao próprio fato do termo ter sido introduzido por estes autores.

O termo inovação, quando explicitado nos artigos, assumiu variados conceitos e aplicação que estiveram associados à introdução de novos programas educacionais e práticas pedagógicas, adoções de tecnologias de informação e comunicação e, até mesmo, a necessidade de reformulações de identidade profissional. A inovação aparece também atrelada à necessidade de interação, colaboração e construção coletiva, o que mantém uma relação com o próprio campo social da educação.

Recomendações de estudos são sugeridas para aprofundar o papel, efeitos e impactos da atuação das CoPs para a promoção da inovação. Como o propósito deste artigo foi traçar um panorama geral do uso de CoPs inter-relacionando com a inovação, sugere-se identificar como as CoPs são empregadas visando a inovação de práticas entre públicos específicos, como professores e alunos. Estudos voltados por segmentos educacionais, especialmente na educação infantil, fundamental e médio também são sugeridos, pois observou-se baixa incidência de estudos neste segmento. Sugere-se ainda o aprofundamento de pesquisas que retratem a infraestrutura e utilização de mídias e dispositivos para suporte à inovação nas CoPs.

\section{REFERÊNCIAS}

AL-SHAHRANI, F.; MOHAMMAD, H. Conceptual model of successful educational online community of practice for Kingdom of Saudi Arabia. International Journal of Emerging Technologies in Learning, v. 9, p. 4-10, 2014. 
ANDREW, N.; TOLSON, D.; FERGUSON, D. Building on Wenger: communities of practice in nursing. Nurse Education Today, v. 28, p. 246-252, 2008.

ARDICHVILI, A., PAGE, V.; WENTLING, T. Motivation and barries to participation in virtual knowledge-sharing communities of practice. Journal of Knowledge Management, v. 7, n. 1, p. 647-77.

BROWN, J. S.; DUGUID, P. Organizational learning and communities-of-practice: Toward a unified view of working, learning, and innovation. Organization Science, v. 2, n. 1, p 40-57, 1991.

BROWN, J. S.; DUGUID, P. knowledge and organization: a social-practice perspective. Organization Science, v. 12, n. , p. 198-213, 2001.

BRAUN, V.; CLARKE, V. Using thematic analysis in psychology. Qualitative Research in Psychology, v. 3, n. 2, p. 77-101, July 2008.

CABRERA, D.; ROY, D.; CHISOLM, M. S. Social media scholarship and alternative metrics for academic promotion and tenure. Journal of the American College of Radiology, v. 15, n. 1, 2018.

CALDWELL, H; HEATON, R. The interdisciplinary use of blogs and online communities in teacher education. The International Journal of Information and Learning Technology, v. 33, n. 3, p. 142-158, 2016.

CHEN, H. C. et al. The health professions education pathway: preparing students, residents, and fellows to become future educators, teaching and learning in Medicine. 2016. Teaching and Learning in Medicine, $v$. 29, n. 2, 2017.

$\mathrm{CHIKH}$, A., BERKANI, L. Communities of practice of e-learning, an innovative learning space for e-learning actors. Procedia Social and Behavioral Sciences, v. 2, p. 5022-5027, 2010.

CHU, M; KHOSLA, R. Index evaluations and business strategies on communities of practice. Expert Sys Appl, v. 36, v. 2, p. 1549-1558, 2009.

COCHRANE et al., T. Riding the wave of BYOD: developing a framework for creative pedagogies. Research in Learning Technology, v. 22, p.1-14, 2014.

CONFORTO, E. C., AMARAL, D. C.,SILVA, S. L. Roteiro para revisão bibliográfica sistemática: aplicação no desenvolvimento de produtos e gerenciamento de projetos. In: CONGRESSO BRASILEIRO DE GESTÃO DE DESENVOLVIMENTO DE PRODUTO, 8., 2011, Porto Alegre. Anais [...]. Porto Alegre: UFRS, 2011.

CORREA, J. M; MARTÍNEZ-ARBELAIZ, A.; GUTIERREZ, L. P. Between the real school and the ideal school: another step in building a teaching identity, Educational Review, v. 66 n. 4, p. 447-464, 2014.

CORREIA, A. M. R.; PAULOS, A.; MESQUITA, A. Comunidades de prática: factores críticos de sucesso para a inovação e a partilha de conhecimento. In: CONFERÊNCIA DA ASSOCIAÇÃO PORTUGUESA DE SISTEMAS DE INFORMAÇÃO, 8., 2008, Setubal. Atas [...]. Setubal: Instituto Politécnico Setúbal, 2008.

COX, A. M. What are communities of practice? A comparative review of four seminal works. Journal of Information Science, v. 31, n. 6, p. 527-540, 2005.

CUMMING-POTVIN, W. Social Justice, Pedagogy and multiliteracies: developing communities of practice for teacher education. Australian Journal of Teacher Education, v. 34, n. 3, June 2009.

DAVIS, N. E.; ROBLYER, M. D. Preparing teachers for the "schools that technology built". Journal of Research on Technology in Education, n. 37, v. 4, p. 399-409, 2005.

FRANCO, M. C. B.; RAMÍREZ, R. C..; MONTOYA, M. S. R. Prácticas educativas abiertas y apropiación tecnológica: el caso de la Comunidad Latinoamericana Abierta y Regional de Investigación Social y Educativa (CLARISE).

Revista de Universidad y Sociedad del Conocimiento, v. 11, n. 1, p. 4-17, 2014.

GARROW, A.;TAWSE, S. An exploration of the assessment experiences of new academics as they engage with a community of practice in higher education. Nurse Education Today, v. 29, n. 6, p. 580-584, 2009.

GOODYEAR, V. A., CASEY, A. A. Innovation with change: developing a community of practice to help teachers move beyond the honeymoon of pedagogical renovation, Physical Education and Sport Pedagogy, v. 20, n. 2, p. 186-203, Sep. 2013. 
GOODYEAR, V. A.; CASEY, A.; KIRK, D. Tweet me, message me, like me: using social media to facilitate pedagogical change within an emerging community of practice. Sport, Education and Society, v.19, n. 7, p. 927-943, 2014.

GUNAWARDENA, C. N. et al. New model, new strategies: instructional design for building online wisdom communities. Distance Education, v. 27, n. 2, p. 217-232, 2006.

JHO, H.; HONG, O.; SONG, J. An analysis of STEM/STEAM teacher education in Korea with a case study of two schools from a community of practice perspective. Eurasia Journal of Mathematics, Science e Technology Education, v. 12, n. 7, p. 1843-1862, 2016.

LATIF, F. TELFest: an approach to encouraging the adoption of educational Technologies. Research in Learning Technology, v. 25, p. 1-14, 2017.

LAVE, J.; WENGER E. Situated learning: legitimate peripheral participation. New York: Cambridge University Press, 1991.

LEAL-SOTO, F. L.; HERNANDEZ, M. A.; PARADA, M. I. Liderazgo directivo y condiciones para la innovación en escuelas chilenas: el que nada hace, nada teme. Estudios Pedagógicos XLII, n. 2, p. 193-205, 2016.

LEE, M. Knowledge management and innovation management: best practices in knowledge sharing and knowledge value chain Ming-Chang Lee. International Journal Innovation and Tecnology, v. 19, n. 2, p 206-226, 2016.

LI, C. et al. Evolution of Wenger's concept of community of practice. Implement Sci, v. 4, n. 1, p. 1-8, Mar. 2009.

OAKMAN, J. Beyond coursework: developing communities in an online program of study. Journal of Information Technology Education: Innovations in Practice, v. 15, p. 167-179, 2016.

OKADA, A; SHERBORNE, T. 2018. Equipping the next generation for responsible research and innovation with open educational resources, open courses, open communities and open schooling: an impact case study in Brazil. Journal of Interactive Media in Education, v. 1, p. 1-15, 2018.

PLESSIS, M. The role of knowledge management in innovation. Journal of Knowledge Management. v. 11, n. 4, p. 20-29, 2007.

SMEDLEY, A.; MOREY, P. Improving learning in the clinical nursing environment: perceptions of sênior Australian bachelor of nursing students. Journal of Research in Nursing, v. 15, n. 1, p. 75 - 88, 2009.

SMITH, S. U.; HAYES, S; SHEA, P. A Critical review of the use of Wenger's community of practice (cop) theoretical framework in online and blended learning research, 2000-2014. Online Learning, v. 21, n.1, p. 209-237, Mar. 2017.

TAVARES, F. G. O conceito de inovação em educação: uma revisão necessária. Revista do Centro de Educação Universidade Federal de Santa Maria, v. 44, 2019.

TAYLOR, L. K. et al. Affirming plural belonging: building on students' family-based cultural and linguistic capital through multiliteracies pedagogy. Journal of Early Childhood Literacy, v. 8, n 3, p. 269-294, 2008.

TIDD, J., BESSANT, J. Gestão da inovação. 5. ed. Porto Alegre: Bookman, 2015.

TIDD, J. ; BESSANT, J.; PAVITT, K. Gestão da inovação. 3. ed. Porto Alegre: Bookman, 2008.

VRASIDAS, C; ZEMBYLAS, M. Online professional development: lessons from the field. Education + Training, v. 46, n. 6-7, p. 326-334, 2004.

WENGER E. Communities of practice: the structure of knowledge stewarding. In: DESPRES, C.; CHAUVEL, D. Knowledge Horizons: the present and the promise of knowledge management. Editora ButterworthHeinemann: Massachusetts, 2012. cap. 10.

WENGER, E. C. A brief overview of the concept and its uses. 2015. Disponível em: https://wengertrayner.com/introduction-to-communities-of-practice. Acesso em: 10 jan. 2020. 
WENGER, E. C.; SNYDER, W. M., Communities of practice: the organizational frontier. Harvard Business Review, p. 139-145, Jan./Fev. 2000. Disponível em:https://hbr.org/2000/01/communities-of-practice-theorganizational-frontier. Acesso em: 20 nov. 2019.

WILBERT, J. K. W. Características de VCoPs que influenciam processos de inovação: estudo de caso em uma empresa pública brasileira. 2015. Dissertação (Mestrado) - Universidade Federal de Santa Catarina. Florianópolis, SC, 2015.

WILBERT, J. K. W. Comunidade de prática. In: PRIM, M. A. et al. (org.) Inteligência para inovação. Capivari de Baixo: Editora Fucap, 2019. p. 191-211.

WILBERT, J. K. W. et al. O uso de comunidades de prática virtuais (vcops) para fins de inovação segundo percepção de seus membros. Perspectivas em Gestão \& Conhecimento, João Pessoa, v. 7, p. 109-125, mar. 2017.

WINKS, L.; GREEN, N.; DYER, S. Nurturing innovation and creativity in educational practice: principles for supporting faculty peer learning through campus design. High Education, n. 80, p. 119-135, 2020.

Disponível em:https://link.springer.com/article/10.1007/s10734-019-00468-3. Acesso em: 01 mar. 2020. 